This item was submitted to Loughborough's Research Repository by the author.

Items in Figshare are protected by copyright, with all rights reserved, unless otherwise indicated.

\title{
Design, development and validation of a workplace cyberbullying measure, the WCM
}

PLEASE CITE THE PUBLISHED VERSION

http://dx.doi.org/10.1080/02678373.2016.1255998

\section{PUBLISHER}

(c) Taylor \& Francis

\section{VERSION}

AM (Accepted Manuscript)

\section{PUBLISHER STATEMENT}

This work is made available according to the conditions of the Creative Commons Attribution-NonCommercialNoDerivatives 4.0 International (CC BY-NC-ND 4.0) licence. Full details of this licence are available at: https://creativecommons.org/licenses/by-nc-nd/4.0/

\section{LICENCE}

CC BY-NC-ND 4.0

\section{REPOSITORY RECORD}

Farley, Samuel, lain Coyne, Carolyn Axtell, and Christine A. Sprigg. 2016. "Design, Development and Validation of a Workplace Cyberbullying Measure, the WCM". Loughborough University. https://hdl.handle.net/2134/22114. 


\title{
Design, development and validation of a workplace cyberbullying measure (WCM)
}

\author{
Samuel Farley ${ }^{1}$, Iain Coyne ${ }^{2}$, Carolyn Axtell ${ }^{1}$ and Christine Sprigg ${ }^{1}$
}

\author{
Author Note \\ ${ }^{1}$ Institute of Work Psychology, University of Sheffield Management School \\ ${ }^{2}$ School of Business and Economics, University of Loughborough
}

Keywords: Cyberbullying, workplace bullying, measure development, bullying behaviours

Correspondence concerning this article should be sent to Samuel Farley, Room 2-22,

Department of Psychology, Western Bank, Sheffield, S10 2TP (email:

s.j.farley@sheffield.ac.uk) 


\begin{abstract}
Cyberbullying research is beginning to expand from its roots in the youth context into the organisational realm. However, a lack of psychometrically sound scales that capture the diverse features of technological communication has hindered workplace cyberbullying research. The purpose of this study was to develop a valid and reliable measure to assess cyberbullying across disparate working populations. Three separate studies involving a total of 944 respondents from different work settings were conducted to establish a 17-item workplace cyberbullying measure (WCM). Further validation of the WCM was established by assessing correlations with a wide range of variables. Regression analysis demonstrated that the measure explained significant incremental variance in emotional exhaustion over and above existing harassment constructs. Justification for developing the WCM is presented, along with implications for research and practise.
\end{abstract}




\section{Introduction}

Cyberbullying propagated by children and adolescents has been the focus of research attention since the early 2000s. However, while researchers know an increasing amount about traditional workplace bullying, the extant literature on workplace cyberbullying is limited. Evidence exists that cyberbullying occurs within organisational environments (Baruch, 2005; Farley et al, 2015; Privitera \& Campbell, 2009) and has negative implications for those who experience it (D’Cruz \& Noronha, 2013; Snyman \& Loh, 2015). Some authors argue that cyberbullying may have more severe outcomes than traditional bullying (Coyne et al, 2016; Dooley, Pyzalski, \& Cross, 2009) because certain features of cyberbullying (e.g. physical separation of perpetrator and target, perpetrator anonymity) increase fear and uncertainty (Ford, 2013). These features have led human resources professionals to recognise cyberbullying as a workplace stressor, although they are grappling with the complexities of cases that occur outside of working hours (West et al, 2014).

Before systematic research can adequately address cyberbullying, validated measurement tools need to be developed (Tokunaga, 2010). Despite growing awareness of workplace cyberbullying, the current measurement of the phenomenon is limited. Research is either restricted by its focus solely on email harassment (Baruch, 2005) or on related, yet conceptually different concepts (e.g. cyber incivility, Giumetti, et al. 2012). The current research attempts to fulfil the measurement need by detailing the development of a workplace cyberbullying measure.

\section{Understanding and Defining Workplace Cyberbullying}

Within the child/adolescent research context a multitude of cyberbullying definitions have been proposed (Kowalski, Giumetti, Schroeder \& Lattanner, 2014). Common aspects of 
these definitions include using technology as the vehicle for harassment, intent to harm, repetition and a power imbalance between the perpetrator and victim (Smith et al, 2008).

Less research has addressed work-related cyber harassment, yet this body of literature includes two constructs that can inform our understanding of workplace cyberbullying: cyber incivility and cyberaggression. Cyber incivility has been defined as "communicative behaviour exhibited in computer-mediated interactions that violate workplace norms of mutual respect" (Lim \& Teo, 2009, p.419). Cyber incivility closely mirrors the concept of face-to-face incivility which refers to low intensity deviant acts enacted towards others with ambiguous intent to harm (Anderson \& Pearson, 1999). Conceptually, cyber incivility differs from cyberbullying because it can refer to a single act, the acts involved are less severe than those which reflect cyberbullying and there is no requirement for a power disparity between perpetrator and target for cyber incivility to occur.

Weatherbee and Kelloway (2006) define Cyberaggression as "aggression expressed in a communication between two or more people using ICTs, wherein at least one person in the communication aggresses against another in order to effect harm.” (p.461). Research on traditional forms of aggression and bullying has outlined how they differ (Schat \& Kelloway, 2005). Firstly, bullying involves repeated acts, whereas aggression can refer to a single act. Secondly, bullying involves a power disparity between perpetrator and victim, which is not a prerequisite of aggression. Finally, aggression is enacted intentionally, but this is not a defining aspect of many workplace bullying definitions (Einarsen, 2000; Einarsen, Hoel, Zapf \& Cooper, 2011; Matthiesen \& Einarsen, 2007).

As noted by Spector (2014) before empirical work can address a construct, it must be theoretically conceptualised and differentiated from related constructs. Therefore distinguishing cyberbullying from related cyber harassment constructs can facilitate 
understanding of how conceptual differences affect antecedents, outcomes and coping strategies. However, even though researchers have developed cyber constructs to represent online versions of aggression and incivility, a relevant question concerns whether workplace cyberbullying needs to be investigated as a separate form of bullying. This is an especially pertinent question in the field of workplace harassment as the development of multiple constructs may not be yielding new insights or adding value to the research field (Hershcovis, 2011).

Similar to cyber incivility and cyberaggression, cyberbullying shares the same definitional criteria as its offline equivalent, including repeatedly experiencing behaviours described as inappropriate, negative and hostile (D'Cruz \& Noronha, 2013) and a power imbalance between perpetrator and victim (Pivitera \& Campbell, 2009; Zhang \& Leidner, 2014). Accordingly, workplace cyberbullying has been conceptualised simply as 'bullying via technology' (Coyne et al, 2016). However, researchers have noted that cyberbullying possesses unique characteristics which may facilitate a different bullying experience for those involved (Kowalski et al, 2014).

Cyberbullying is enacted through technologies, which can span time and space boundaries allowing perpetrators greater access to victims (Smith, 2012). Traditionally, workplace bullying has occurred "at work" but perpetrators and targets do not need to be physically co-located for cyberbullying to occur. This allows perpetrators to send communications whenever they please and it can facilitate anonymity which is the extent that a perpetrator's identity is concealed (Ford, 2013). Anonymous cyberbullying can occur within the working context as employees can create fake email accounts or use pseudonyms to disguise their identity (D’Cruz \& Noronha, 2013). 
A further difference concerns the permanence of certain cyberbullying acts, which distinguishes them from the transience of most traditional bullying behaviours. Website blogs, emails and social media postings are permanently accessible once published, they can therefore be repeatedly viewed and seen by a much larger audience. Although some traditional bullying behaviours (e.g. physical isolation) may represent a permanent change which is observable to bystanders, the permanence associated with cyberbullying refers to the permanent record of the original act.

Finally, the audience range can be much greater when cyberbullying occurs. Online communications can transcend the barriers of a work group such that private conflicts can be observed by all organisational members and even members of the public. For example, D'Cruz and Noronha (2013, p.335) described a situation where employees from the Indian I.T sector used a social networking website to air grievances about their managers. The employees posted comments about managers working styles, individual characteristics and personal relationships. Each post triggered additional comments from bystanders who were often unknown to the person being discussed.

Although the existence of these features may produce experiential differences between workplace cyberbullying and traditional workplace bullying, we contend that workplace cyberbullying and traditional workplace bullying are conceptually similar. The way that power and repetition are exercised through technology may be different to the faceto-face context (for example anonymity may represent a power disparity) yet cyberbullying is still characterised by repetition and power imbalance. We therefore define workplace cyberbullying as: a situation where over time, an individual is repeatedly subjected to perceived negative acts conducted through technology (e.g. phone, email, web sites, social media) which are related to their work context. In this situation the target of workplace cyberbullying has difficulty defending him or herself against these actions. 
Similar to many traditional workplace bullying definitions, intent to harm has not been included as a defining criterion. It has been argued that intent should not be used to operationalise bullying in the workplace because of the complexities surrounding how to establish a perpetrator's real intentions (Einarsen et al, 2011). Establishing intent is even more difficult during online communication because ICTs do not transmit the full range of communication cues (Daft \& Lengel, 1986). Additionally, because cyberbullying acts sometimes leave a digital footprint, perpetrators may be even more careful to disguise behaviours to prevent being reported.

Conceptualising cyberbullying in the same manner as traditional bullying prompts the question of whether new measurement tools are actually needed. As commentators argue that different types of bullying behaviour should be investigated and evaluated differently (Hoel, Faragher \& Cooper, 2004; Escartin et al, 2010) we contend that tailored methods are necessary. It has also been argued that multiple measures are needed for each form of abuse because this facilitates greater understanding of the construct (Bowling, Camus \& Blackman, 2015). Existing cyber harassment measures are reviewed in the following section.

\section{Measurement}

\section{Cyber Specific Measures}

Behavioural measures have been developed to assess cyber incivility (Lim \& Teo, 2009), cyberaggression (Weatherbee, 2007) and cyberbullying (Coyne et al, 2016; Hong et al, 2014). Yet the cyber incivility and cyberaggression scales are not suitable for cyberbullying research because both scales only measure email and instant messaging behaviours. In order to fully appraise cyberbullying, a scale would need to consider a broader spectrum of ICTs. Indeed, a limitation of measures that reference the media used to channel an act is that they may become outdated when the media becomes obsolete. Furthermore, neither measure 
captures the cyberbullying criterion of power disparity between perpetrator(s) and victim, thus they lack construct validity.

One measure developed to assess cyberbullying was published by Hong et al. (2014) however there are a number of potential drawbacks to this scale. Firstly, it is not reported whether a measure development methodology was used to validate the instrument. Secondly, it is unclear how the scale assesses power imbalance. Finally, the measure was developed in the Taiwanese context, therefore the terminology and phrasing of items may be difficult for Western employees to understand.

A dedicated cyberbullying instrument was also used by Snyman and Loh (2015) who investigated workplace cyberbullying among white collar employees using the 21 item cyberbullying experience survey (Doane, Kelley, Chiang \& Padilla, 2013). This measure contains a number of cyber specific items, including 'Has someone posted an embarrassing picture of you electronically where other people could see it'. However, the measure does not include any items related to the work context as it was developed to assess cyberbullying among college students.

The Cyber NAQ

A popular approach has been to adapt the well-known negative acts questionnaire (NAQ; Einarsen, Hoel \& Notelaers, 2009) to assess workplace cyberbullying (Coyne et al, 2016; Farley et al, 2015). The cyber version of the NAQ has strong construct validity, capturing both repetition and power imbalance (if a global self-report item is included). Yet, adapting the NAQ may not adequately capture the full workplace cyberbullying domain as it was originally developed to assess traditional bullying. Accordingly, unique cyberbullying behaviours are not included in the scale (e.g. carbon copying, having personal information shared online) which means the cyber NAQ lacks content validity. 
The development of a workplace cyberbullying construct therefore broadens the scope of behaviours that can occur within the workplace bullying framework. To promote systematic research efforts on workplace cyberbullying these behaviours initially need to be identified. After identification a tailored scale should be developed to assess workplace cyberbullying rather than simply adding behavioural items to existing scales. Researchers have added cyberbullying items to traditional bullying measures to account for cyber-specific behaviours (Fox \& Cowan, 2015). However adding items to existing scales can change how a measure relates to other variables (Keller \& Dansereau, 2001) which has implications for meta-analysis because the nature of the same scale changes over time. Keller and Dansereau (2001) therefore suggested that "one might be better off starting with a new scale rather than enhancing the old scale" (p.139). Given these arguments, the aim of this study was to develop a valid and reliable workplace cyberbullying measure.

\section{The Current Study}

Three multiphase studies, guided by Hinkin's (1998) measure development methodology were conducted to develop the WCM. Two criteria were considered during these studies. Firstly, the measure should be applicable to employees from different industries and working sectors. This facilitates future research by enabling researchers to investigate the phenomenon in different settings, as well as enabling comparisons across samples (Einarsen et al, 2009). Secondly, to counter the criticism of the limited scope of current measures, the scale should assess behaviours perpetrated through a broad spectrum of communication technologies.

\section{Study One: Instrument Development}

Study One involved two separate phases: (1) collecting descriptions of workplace cyberbullying behaviours and converting them into measurement items; followed by (2) assessing face validity. 


\section{Phase One: Item Generation}

Both inductive and deductive methods were used to generate items (Day, Paquet, Scott \& Hambley, 2012). Initially a deductive process was followed as the researchers independently identified 13 workplace cyberbullying behaviours by searching the cyber harassment literature. Data were then gathered using a more inductive process that involved obtaining behavioural descriptions from the working population.

Behavioural descriptions were generated using an online survey. Respondents were recruited from five data collection streams: (1) Three UK teaching unions and a marketing organisation sent the survey to their members. (2) An email was distributed on a UK Academic Mailing List Service called JISC Mail. JISC mail is a website that facilitates communication on educational and research interests, members tend to be from research communities although private sector employees also subscribe. Members sign up to different mailing lists which distribute information on a particular interest via email. (3) Posts to the survey were distributed through the social media websites LinkedIn and Twitter. (4) Data were collected in the Australian Public Sector (APS) through collaboration with researchers based in Australia. (5) Data were collected at a workshop attended by 14 individuals from academia and industry.

Respondents were asked to describe up to three behaviours they felt constituted workplace cyberbullying based on the following definition "persistent, repeated negative behaviour enacted through communication technologies (e.g. phone calls, emails, text messages, social networking websites) by individuals or groups, which creates a hostile work environment. Over time, this impacts negatively on the person facing the behaviour and places them in an increasingly inferior position". Questionnaire instructions stated that the behaviours did not necessarily have to be experienced during work hours and that 
cyberbullying could occur through various media, including email, telephone calls, text messages, social networking websites, regular websites, instant messaging, chat rooms and video conferencing.

In total, 248 completed surveys were returned which generated 604 behavioural descriptions. Analysis revealed that the majority of respondents $(71.1 \%)$ were female and their ages ranged from 23 to 68 with a mean age of 45 years $(S D=11.24)$. They held job roles including teacher, marketing executive and auditor. An inductive method was used to sort the behavioural descriptions into categories. Hinkin (1998) notes that once descriptions have been generated, they should be classified into categories or sorted using content analysis of key words or themes. Behavioural descriptions were coded and organised into categories under a heading that best described the text content. After analysing all the descriptions, 32 categories were developed, examples include gossip, exclusion, unreasonable work demands, emails at unsociable hours, photos and jokes*.

Sorting the descriptions into categories enabled the removal of identical behavioural descriptions, while behaviours that were too specific to a single working context were also removed. After eliminating redundant descriptions, 95 workplace cyberbullying behaviours remained. These descriptions were combined with the behaviours identified during the deductive search of the literature $(n=13)$, leaving 108 behavioural descriptions available for item writing procedures.

Recommendations were followed to convert behavioural descriptions into items (Hinkin, 1998). A total of 40 behavioural descriptions were discarded during the item writing process. Items considered ambiguous or particularly unlikely to occur in a working context were removed from the item pool. Additionally, items that referenced a specific

\footnotetext{
${ }^{*}$ The full list of categories is available from the first author.
} 
communication method (e.g. email, text, social media) were excluded as the evolution of technology can quickly render medium specific acts as obsolete (Menesini et al, 2011).

To ensure that all items were cyber specific the following pre-item instructions were developed: "The following questions refer to acts conducted through technology that are related to your work context. These technologies can include: Text messaging; pictures/photos/video clips; phone calls; email; instant messaging; social networking websites; video software and general websites. Please rate how often over the last six months, you have been subjected to the following negative work-related acts through technology. Please note: these questions do NOT refer to face-to-face behaviours." To account for new ICT developments, these instructions can be adapted when the referenced media become outdated and when new forms of technology-mediated communication emerge. To further tailor the measure to the cyber context, items were worded in a manner that reflected the online context, as we used terms including "messages", "communications", "copy" and "share" which capture common aspects of cyber communication.

Content validity was established during the item writing phase as behaviours from the different categories were converted into items, which produced a broad item pool comprising 68 items. A comprehensive item pool facilitates content validity because the fundamental goal of item generation is to include all possible contents that might comprise the construct (Loevinger, 1957).

Phase Two: Face Validity Assessment

Hardesty and Bearden (2004) note that content validity refers to the spread of items and whether they represent the full proportion of a construct, whereas items are face valid if they represent the intended construct, but their spread is not considered. A common method 
of assessing face validity involves employing subject matter experts (SMEs) who judge items according to the extent that they represent the given construct (Hardesty \& Bearden, 2004). Sample \& Procedure

Eight SMEs were asked to rate (on a scale of $1=$ strongly disagree to $7=$ strongly agree) all 68 items according to the extent that they felt items were consistent with the workplace cyberbullying definition. Six SMEs were experts in workplace harassment, one was an expert in computer-mediated communication and the other was a youth cyberbullying expert. A text box was also provided after each item which enabled SMEs to make notes on the clarity, consistency and wording of the items.

Feedback from two SMEs stated that workplace cyberbullying should be defined without assuming that it creates a 'hostile work environment'. Instead the relationship between workplace cyberbullying and outcomes should be examined empirically using appropriate research methods. We therefore changed the workplace cyberbullying definition to: a situation where over time, an individual is repeatedly subjected to perceived negative acts conducted through technology (e.g. phone, email, web sites, social media) which are related to their work context. In this situation the target of workplace cyberbullying has difficulty defending him or herself against these actions. Due to this definitional change, all the behavioural descriptions produced during phase one of the study were re-examined to ensure they were still consistent with the adapted definition. No items were removed as a result of this examination.

Several methods were used to guide item retention (Hardesty \& Bearden, 2004). Firstly, the 'sumscore' rule (Lichtenstein, Netemeyer \& Burton, 1990) was used to evaluate the representativeness of the items, which is the total score for an item across all SME ratings. A guide to item retention was to remove items that received a mean rating of 2.4 and lower, indicating clear disagreement on face validity. Items that received a mean score of 
between 2.5 and 4.4 would be examined to either re-write or delete, while items that received a mean score of 4.5 and above would generally be retained. However, Hinkin (1998) notes that scale development involves "a bit of art as well as a lot of science" (p. 118). Therefore items scores were not examined in isolation.

Once the mean score for each item had been calculated, a document was produced which contained the item, its mean face validity rating and any comments the SMEs had offered regarding wording or clarity. This document was reviewed at a meeting where the research team discussed each item based upon different criteria, including ease of understanding, number of similar items retained and how commonly it had been referenced by participants.

A total of 34 items were retained. Only one item was removed due to receiving a mean rating below 2.4 (Had a colleague use technology-mediated communications to deliver bad news). In total, 31 items were rated between 2.5 and 4.4 ( 21 were discarded and 10 were rewritten and retained). Furthermore, 36 items received ratings higher than 4.5 (12 were removed, 14 were rewritten and retained and 10 were accepted outright). A severity assessment was then performed to ensure that the 34 retained items were perceived as sufficiently negative, rather than low-intensity behaviours which may better reflect cyber incivility. A sample of six new SMEs and 11 employees from a large public sector organisation were asked to rate the severity of each item on a scale, whereby $1=$ no harassment and $10=$ maximum severity. The assessment confirmed that the items were perceived as sufficiently negative as $32(94.12 \%)$ items received a mean severity rating greater than 5.00, whereas just two $(5.88 \%)$ received a mean rating lower than 5.00 (rated 4.82 and 4.12 respectively).

\section{Study One Summary}


During Study One a 34-item workplace cyberbullying scale was established. In the first phase, inductive and deductive methods were used to create an item pool $(n=68)$. In the second phase, each item's face validity was assessed which resulted in the removal of 34 items. These processes produced a 34-item workplace cyberbullying measure that could be distributed to employees.

\section{Study Two: Initial measure validation}

Study Two was conducted to validate the 34-item measure on a new sample of employees. The study had three main aims: (1) to identify the underlying factor structure (2) to assess reliability and validity and (3) to refine the scale by removing unreliable and unrepresentative items.

\section{Sample \& Procedure}

The 34-item workplace cyberbullying measure (WCM) was distributed across five data collection streams. They comprised $79(18.6 \%)$ individuals from the researcher's network; ten (2.4\%) employees from a large multinational leadership and talent consultancy firm; six (1.4\%) volunteers at a UK mental health charity; 194 (45.8\%) individuals from JISC mail distribution lists that were different from those used in the Study One and 135 (31.8\%) employees from a large city council. An online survey was distributed via email to each of the data collection streams with the exception of the city council who posted information regarding the study on their intranet. This methodology allowed direct access to people who used at least one form of technology in relation to their work, although due to the nature of the method response rates cannot be calculated.

Participants comprised 424 employees aged between 19 and 69 years $(M=41$ years, $\mathrm{SD}=11.90) ; 55.3 \%$ of participants were female. All three sectors were represented within the 
sample and job roles included IT manager, consultant and social worker. Most respondents worked 35 hours or more per week (79\%), and they had a mean tenure of 20 years $(\mathrm{SD}=$ 11.96).

Respondents were asked how often over the last six months they had experienced each cyberbullying item through technology in relation to their work context. The response options were 'never', 'now and then', 'at least monthly', 'at least weekly' and 'daily'. After completing the cyberbullying items, respondents were presented with the refined workplace cyberbullying definition. They were then asked 'Using this above definition, please state whether you have been cyberbullied at work over the last six months?' The response categories were 'No', 'Yes, now and then', 'Yes, monthly', 'Yes, weekly' and 'Yes, almost daily'. A combination of behavioural items with a self-report definition question is recommended as this allows analysis of respondents who self-label as victims, as well as exposure to bullying behaviours (Nielsen, et al., 2010). Furthermore, a self-labelling definition item should be included after behavioural items to ensure that the power imbalance criterion has been met. In the above definition this refers to the targets inability to defend themselves, which could arise from formal and informal power differences (Branch, Ramsay \& Barker, 2013).

Analysis of the self-report item revealed that only two respondents $(0.5 \%)$ felt they were cyberbullying victims on a daily basis, while six (1.4\%) felt victimised on a weekly basis. The self-report item was strongly correlated with the 34 -item scale $(\mathrm{r}=.55, \mathrm{p}<.001)$ which suggests that individuals who experience more cyberbullying behaviours more regularly, also tend to perceive a power imbalance between themselves and the perpetrator(s) victims. Spearman's correlation was used for this analysis given the ordinal level response options to the self-report item. 
It is important to establish that a strong correlation exists between the self-report item and the behavioural scale if researchers intend to use the scale as a cyberbullying measure. This is because the self-report item measures the power disparity element of the construct which is not captured by the behavioural scale. The self-report item was not used for any further analysis as the aim of this study was to determine the factor structure and reliability of the behavioural items.

Data were assessed for missing values, outliers and normality. The distribution of the cyberbullying scale $(\mathrm{M}=1.45, \mathrm{SD}=.37)$ was non-normally distributed, with a positive skew of $1.49(\mathrm{SE}=.12)$ and a kurtosis of $2.59(\mathrm{SE}=.24)$. Positive skew was expected as similar constructs display comparable distributions (Baillien, Rodriguez-Munoz, Van den Broeck \& De Witte, 2011; Weatherbee, 2007). An initial examination demonstrated that the scale was highly reliable $(\alpha=.94)$. Correlated item totals were also examined to determine whether inconsistent items could be removed from the measure. Kim and Mueller (1978) suggest removing items correlating below the .4 level. On this basis, four items were removed.

Before conducting factor analyses, similar to Einarsen et al. (2009) in their analysis of the NAQ, the 'at least weekly' and 'daily' categories were collapsed into in a single response category because the latter category was rarely selected. Further, as recommended by Hinkin (1998) if the sample size is sufficiently large $(n>400)$ data can be split in half, with exploratory factor analysis (EFA) performed on one half and confirmatory factor analysis (CFA) on the other. Researchers maintain the value of using this approach; Worthington and Whittaker (2006) state that exploratory methods are able to capture the correct factor model in most cases and the hypothesised factor structure should be replicated on a separate sample. Similarly, Kim, Egan and Tolson (2015) suggest that using both EFA and CFA can produce more accurate measurement. 
Principal axis factoring with oblique rotation was performed on the remaining 30 WCM items. Overall, as the communalities after extraction were below an average of .7 and the sample size was lower than 250 , a scree plot was used to determine the number of factors to extract (Field, 2009). The scree plot revealed two salient factors and to aid interpretation the EFA was respecified to force a two-factor solution. Two items with communalities after extraction of below .3 were removed due to their lack of shared variance and two further items were then removed because the difference in their loadings across factors was less than .15 from the higher loading factor (Worthington \& Whittaker, 2006). After removal of these items the EFA was re-specified for the remaining 26 indicators. This analysis was originally conducted in SPSS, although sensitivity analysis conducted using Mplus confirmed that the results were the same regardless of the statistical package used.

The Kaiser-Meyer-Olkin measure verified the sampling adequacy, KMO = .91 and all KMO values for individual items were > .82, above the acceptable limit of .5 (Field, 2009). All 26 items achieved factor loadings of .40 or greater (Table 1), and the two factor structure seemed to represent constructs of work-related cyberbullying (involving acts related to an individual's working experience) and person-related cyberbullying (encompassing acts of a more personal nature). This structure is theoretically similar to the one underlying traditional workplace bullying (Einarsen et al, 2009).

\section{Table 1 Here}

A CFA was performed to cross-validate the two-factor cyberbullying solution using Mplus version 7. An MLM estimator was selected which provides maximum likelihood parameter estimates with standard errors and a mean-adjusted chi-square to account for nonnormality (Satorra, 2000). The model was assessed using absolute and incremental fit indices (Hu \& Bentler, 1999), including the chi-square statistic, the comparative fit index (CFI), the 
standardised root-mean-square residual (SRMR) and the root-mean-square error of approximation (RMSEA).

The chi-square test of exact fit provides an indication of the difference between the observed covariance matrix and the model covariance matrix. It is often used to evaluate model fit, however it is influenced by sample size, data non-normality and model complexity and thus alternative fit indices are generally preferred (Garrido, Abad \& Ponsoda, 2016). The CFI is a measure of incremental fit that assesses the degree to which the specified model is superior to the null model. Values greater than 0.90 can be considered favourable and values $\geq .95$ indicate good fit (Hu \& Bentler, 1999). The RMSEA is a measure of absolute fit, which is sensitive to model complexity, values lower than .08 and .05 indicate reasonable and close fit, respectively (Garrido et al, 2016). Finally, the SRMR indicates the "standardized difference between the observed and model-implied covariance/correlation matrices" (Garrido et al, 2016, p. 96), values greater than .08 indicate a poorly fitted model.

Initial assessment of the model fit indices indicated that it could be improved $\chi^{2}(298$, $\mathrm{N}=211)=547.35, \mathrm{p}<.001, \mathrm{CFI}=.85, \mathrm{SRMR}=.08, \mathrm{RMSEA}=.06$, RMSEA confidence interval (C.I.) $(.055, .071)$. The scale refinement process involved removing items that displayed regression weights with small loadings on their factor, due to insufficient covariation with other factor items. Modification indices were also inspected to remove items that loaded highly on the other factor. However, we were careful not to remove items that were aligned closely with the definition, such as indicators that received higher face validity ratings and those referenced consistently by participants (for example, items involving threats and abusive language). The respecified model involved 17 items and displayed enhanced fit, $\chi^{2}(118, \mathrm{~N}=211)=171.17, \mathrm{p}<.001, \mathrm{CFI}=.95, \mathrm{SRMR}=.05, \mathrm{RMSEA}=.05$, C.I. $(.030$, .061). All items significantly loaded onto factors and all standardised factor loadings were above 0.5 (Hair, Black, Babin, Anderson \& Tatham, 2006). 
DEVELOPMENT OF A WORKPLACE CYBERBULLYING MEASURE

The two factors were aggregated to form two scales which showed good internal consistencies (work-related, $\alpha=.90$; person-related, $\alpha=.81$ ) that could not be improved by removing items from the scale. Convergent factorial validity was established using composite reliability, which refers to the extent that a group of latent construct items share the measurement of a construct (Fornell \& Larcker, 1981). Values greater than .60 are considered acceptable for convergent validity (Bagozzi \& Yi, 1988). Based on this criterion both factors demonstrated convergent factorial validity (work-related factor $=.90$; person-related factor $=$ $.82)$.

Items and factor loadings can be seen in Table 2. The correlation between the two factors was high $(\mathrm{r}=.86, \mathrm{p}<.01)$ and exceeded the .85 limit recommended by Kline (1998). As such, a further CFA was conducted to determine the fit of a single factor model. Results showed that the single factor fit was acceptable $\chi^{2}(119, \mathrm{~N}=211)=200.33, \mathrm{p}<.001, \mathrm{CFI}=$ .92, SRMR $=.06$, RMSEA $=.06$, C.I. $(.043, .070)$ and demonstrated high reliability $\alpha=.92$. Given that both models fitted the data, the 17-item WCM was distributed to a separate sample during study three for further statistical analysis.

Table 2 Here

\section{Study Three: Further validation - the WCM nomological network}

Study Three had three main aims: (1) establish the nomological network of the workplace cyberbullying measure (WCM) (2) validate the WCM on a separate sample and (3) examine whether the WCM explained significant incremental variance in outcome variables over and above other workplace harassment constructs.

Establishing a measure's nomological network involves determining external convergent and divergent validity by examining relationships with theoretically related and unrelated constructs (Mackenzie, Podsakoff \& Podsakoff, 2011). External convergent validity 
refers to the extent that a scale correlates with measures designed to test similar constructs. Workplace cyberbullying has been conceptualised in the same manner as traditional workplace bullying and it is similar to cyberaggression as it involves experiencing negative interpersonal behaviours through technology. Therefore, convergent validity evidence would be obtained if the WCM correlated positively with these constructs.

External divergent validity is demonstrated when a scale displays weaker or nonexistent associations with theoretically distal variables. To examine the divergent validity of the WCM, two ICT demand variables were examined: ICT hassles and ICT learning expectations. ICT hassles are demands placed on an individual by glitches in software or hardware, such as slow internet speed (Day et al, 2012). In contrast, ICT learning expectations refer to employee's responsibility to stay updated with technological upgrades and enhancements (Day et al, 2012). Theoretically, the relationships between cyberbullying and these variables were expected to be weaker than the relationships between cyberbullying and the workplace harassment variables.

By distributing the WCM alongside established measures it was possible to examine whether the WCM explained significant incremental variance in criterion variables, over and above existing harassment measures. Both emotional exhaustion and interactional justice were examined separately as criterion variables. Maslach, Schaufeli and Leiter (2001) define emotional exhaustion as "feelings of being overextended and depleted of one's emotional and physical resources" (p. 399). Emotional exhaustion is a core dimension of burnout and it can significantly impact on psychological well-being (Sonnentag, Kuttler \& Fritz, 2010). It was examined as an outcome of workplace cyberbullying because research has conceptualised workplace harassment as a stressor that can cause strains (Bowling \& Beehr, 2006). Interactional justice refers to the quality of interpersonal treatment, including the extent that individuals feel they are treated with dignity, respect, truthfulness and propriety (Bies \& 
Moag, 1986). Interactional justice was examined as an outcome variable because researchers have argued that bullying may cause injustice by destroying employee's perceptions of a relatively just world (Parzefall \& Salin, 2010).

\section{Sample \& Procedure}

Data were collected from five sources using an online Qualtrics survey that generated 272 completed responses. The respondents included 19 (7.0\%) individuals from the researcher's network, 65 (23.9\%) employees from a large UK university, 133 (48.9\%) members of JISC mail groups (different groups were contacted from those contacted in studies 1 and 2), 11 (4\%) members of a large higher and further education union and 44 (16.2\%) employees in the workforce and education team of a National Health Service (NHS) hospital. The final sample consisted of $185(68 \%)$ females and $87(32 \%)$ males. They were aged between 16 and $83(\mathrm{M}=43$ years, $\mathrm{SD}=11.47)$ and held job roles including professor, lawyer and nurse. Their average organisational tenure was 8.80 years $(\mathrm{SD}=8.51)$.

\section{Measurement}

Workplace Cyberbullying. The revised 17-item WCM assessed respondent's exposure to cyberbullying over the previous six months. The response categories 'at least weekly' and 'daily' categories were again collapsed prior to statistical analysis. The internal consistency of the 17-item scale was 0.93. As used in Study Two, a separate single-item measured selflabelled cyberbullying.

Traditional workplace bullying was measured using the 9-item negative acts questionnaire short (“S-NAQ”, Notelaers \& Einarsen, 2008). Respondents indicated how often they had experienced bullying behaviours including gossip, exclusion and insults on a five-point scale ranging from 'Never' to 'Daily' $(\alpha=0.89)$. To ensure that respondents knew these behaviours 
referred to face-to-face acts, a statement was added prior to the scale which stated that items referred to offline behaviours and not acts conducted through technology.

Cyberaggression was assessed using an 8-item measure developed by Weatherbee (2007). The scale measures aggression experienced through email or instant messaging (e.g. "During the last 6 months, have you ever received e-mail or instant messages from a subordinate, a coworker, or a supervisor that you would describe as hostile towards you?”). Responses were made on a seven-point scale ranging from 'Never' to 'Very frequently' $(\alpha=.95)$.

ICT hassles and ICT learning expectations were measured using separate factors of Day et al's (2012) ICT demands measure. ICT hassles were measured using five items that assess common hassles people experience when using ICTs (e.g. 'my computer freezes'). The alpha of this scale was 0.79 . ICT learning expectations were measured using three items which measure the extent that respondents are expected to stay current with ICTs at work $(\alpha=.72)$. The response category of both scales was 'Never', 'Infrequently', 'Sometimes', 'Frequently' and 'Almost Always'.

Emotional exhaustion was measured using three items from the Maslach Burnout Inventory (Carlson, Anson \& Thomas, 2003; Maslach \& Jackson, 1981). Respondents were asked how often they felt emotionally exhausted on a seven-point scale ranging from 'Never' to 'Daily' $(\alpha=.90)$.

Interactional justice was measured using three items developed by Bies and Moag (1986) which measures the extent that participants feel treated with dignity and respect at work, such as 'At work I am treated in a polite manner'. The response category was: 'very slightly', 'not at all', 'a little', 'moderately', 'quite a bit' and, 'extremely' $(\alpha=.96)$.

Prior to conducting correlation and regression analysis, the distribution of all variables were examined. The workplace cyberbullying $(\mathrm{M}=1.60, \mathrm{SD}=.49)$ variable was positively 
skewed: skewness $=1.50(\mathrm{SE}=.15)$, kurtosis $=3.18(\mathrm{SE}=.30)$. The other workplace harassment variables were also positively skewed. However similar to Niven, Sprigg and Armitage (2013) responses for most items covered the full range of the scale, and the proportion of respondents who indicated no exposure was in the minority for cyberbullying, cyberaggression and traditional bullying.

\section{Common Method Variance}

The latent variable approach was used to assess whether common method variance (CMV) had affected the relationships between variables (Podsakoff, MacKenzie \& Podsakoff, 2012). This approach involves conducting a CFA whereby items are specified to load on their latent factor, but also on a latent common method variable. Item loadings are then compared to item loadings obtained when a latent CMV variable is not specified. All seven measurement scales were included in the latent CMV analyses and all unstandardized parameter estimates were significant. A comparison of the standardised estimates between the two models showed that out of 48 estimates, only 4 showed a difference that was greater than 0.2 and these were exclusively within the traditional workplace bullying scale. This indicates that although some CMV may have been present it affected a minority of items within a single scale.

Results

Two CFAs were conducted in Mplus version 7 using weighted least squares (WLSMV) estimation. Researchers have used different estimators during the development of workplace bullying scales, depending on whether the data is perceived as ordinal categorical (Einarsen et al., 2009) which complies with WLSMV estimation, or interval (Escartin et al., 2010) which complies with maximum likelihood (ML) estimation. The Study 3 data were initially analysed using ML estimation. However the data were subsequently assessed using a 
WLSMV estimator as the nonnormality that results from skewed response distributions can considerably influence commonly used fit indices when ML is adopted (Nye \& Drasgow, 2011). It was not possible to analyse the Study 2 data using WLSMV as item retention decisions had been made based upon the initial ML estimation results.

It should be noted that using statistical rules of thumb to evaluate model fit is not recommended in all scenarios. Nye and Drasgow (2011) found that the statistical criteria used to evaluate ML model fit are not necessarily appropriate when WLSMV estimation is adopted. Indeed, they suggest that using statistical cut-offs should not be conducted without considering the characteristics of the data, including sample size, normality and model misspecification. Thus it is important to consider other aspect of the model when evaluating fit and to account for theory when evaluating the factor structure (Nye, Brummel \& Drasgow, 2014).

The two-factor model comprising work-related and person related cyberbullying demonstrated relatively good fit: $\chi^{2}(118, \mathrm{~N}=266)=307.38, \mathrm{p}<.001, \mathrm{CFI}=.97, \mathrm{WRMR}=$ 1.12, RMSEA $=.08$, C.I. $(.067, .088)$. The competing single factor model was also specified which produced similar fit indices: $\chi^{2}(119, \mathrm{~N}=266)=366.90, \mathrm{p}<.001, \mathrm{CFI}=.96, \mathrm{WRMR}=$ 1.26, RMSEA $=.09$, C.I. $(.078, .099)$. Similar to Study 2 , the correlation between the latent factors was very high (.87) and factor loadings were all significant and greater than .6 for the single factor model. Therefore, the one dimensional model seemed more appropriate. There is also a theoretical rationale for treating cyberbullying as a unidimensional construct, at least during the early stages of workplace cyberbullying research. The development of a unidimensional measure facilitates research on meaningful preliminary questions, for instance do cyberbullying and traditional bullying relate in the same way to outcomes. Researchers also tend to assess bullying as a unidimensional construct, rather than conducting analysis on separate factors (Notelaers, Baillien, De Witte, Einarsen \& Vermunt, 2013) 
perhaps because it gives a better indication of the overall level of bullying experienced. Further analysis was therefore conducted using the WCM as a single factor measure.

Confirmatory factor analysis was conducted to assess the harassment constructs. A three factor model was initially specified, in which cyberbullying, cyberaggression and traditional workplace bullying loaded onto separate factors $\chi 2(524, \mathrm{~N}=263)=1093.94$, $\mathrm{p}<.001, \mathrm{CFI}=.97, \mathrm{WRMR}=1.27, \mathrm{RMSEA}=.06$, C.I. $(.059, .070)$. The model was compared to a two-factor model where cyberbullying and cyberaggression loaded on one factor and traditional bullying loaded on the other $\chi^{2}(526, \mathrm{~N}=263)=1380.87, \mathrm{p}<.001, \mathrm{CFI}$ $=.95, \mathrm{WRMR}=1.52, \mathrm{RMSEA}=.08$, C.I. $(.074, .084)$. It was also compared to a one-factor model in which all items loaded onto a single factor $\chi^{2}(527, \mathrm{~N}=263)=1576.02, \mathrm{p}<.001$, $\mathrm{CFI}=.94, \mathrm{WRMR}=1.67, \mathrm{RMSEA}=.09$, C.I. $(.082, .092)$. The three factor model displays superior fit to the two-factor and the one factor models, providing support for the construct validity of the WCM.

To assess convergent validity, the WCM was compared with traditional workplace bullying and cyberaggression. As shown by Table 3, convergent validity was established because the WCM was strongly correlated with traditional workplace bullying $(r=.74$, $\mathrm{p}<.01)$ and cyberaggression $(\mathrm{r}=.75, \mathrm{p}<.01)$ (values of $.10, .30$ and .50 denote small, medium and large effect size respectively; Cohen, 1988). Further support for convergent validity was found as experiencing workplace cyberbullying behaviours was significantly correlated with self-labelling as a cyberbullying victim $(\mathrm{r}=.48, \mathrm{p}<.01$; Spearman's correlation). Comparatively, the correlation between experiencing traditional (face-to-face) bullying behaviours and self-labelling as a cyberbullying victim was lower, but also significant $(\mathrm{r}=$ $.36, \mathrm{p}<.01$; Spearman's correlation). Steiger's (1980) z-test was used to statistically compare the size of the correlation between (1) experiencing cyberbullying behaviours and selflabelling as a cyberbullying victim, compared to (2) experiencing traditional bullying 
behaviours and self-labelling as a cyberbullying victim. The z-test revealed that the correlation between the WCM and self-labelling as a cyberbullying victim was significantly stronger that the correlation between experiencing traditional workplace bullying behaviours and self-labelling $(\mathrm{z}=2.6, \mathrm{p}<.01)$. It should also be noted here that only four $(1.5 \%)$ participants perceived themselves as cyberbullying victims on either a weekly or daily basis. A further z-test revealed no significant difference in the correlations between (1) the WCM and self-labelling, compared with (2) cyberaggression and self-labelling $(\mathrm{z}=.26, \mathrm{p}=0.79)$. Furthermore, cyberbullying was positively correlated with ICT learning expectations $(\mathrm{r}=.30$ $\mathrm{p}<.01)$ and ICT hassles $(\mathrm{r}=.21, \mathrm{p}<.01)$. As expected, these correlations were smaller than those observed between cyberbullying and the harassment variables which provides discriminant validity evidence.

Table 3 Here

To examine whether the WCM accounted for incremental variance over traditional workplace bullying and cyberaggression, two hierarchical regressions were conducted with emotional exhaustion and interactional justice as outcome variables. Demographic variables were not included as covariates because they did not display significant correlations with any of the test variables. However, given that the data were comprised of several different samples, the data collection stream was added as a covariate to filter out any variance that could be attributed to a particular sample. In each regression, the sample variable was added in the first step, traditional workplace bullying was added in the second step, cyberaggression was added in the third step and cyberbullying was added in the final step. Table 4 shows that workplace cyberbullying accounted for a small, but significant amount of incremental variance in emotional exhaustion after controlling for traditional workplace bullying and cyberaggression $\left(\mathrm{R}^{2}\right.$ change $\left.=.018, \mathrm{p}<.05\right)$. Cohen's $\mathrm{f}^{2}$ was $.021, \mathrm{f}^{2}$ effect sizes of .02 are considered small, while those around .15 and .30 are considered medium and large 
respectively (Cohen, 1988). Cyberbullying did not account for significant incremental variance in interactional justice when entered after the aforementioned variables $\left(R^{2}=.006, p\right.$ $=.12)$.

\section{Table 4 Here}

\section{Discussion}

In this study we conceptualised cyberbullying using the same criteria used to define traditional workplace bullying: repeated exposure to negative acts and a power disparity between perpetrator(s) and victim. New scales are needed to measure workplace cyberbullying as existing tools either lack construct validity (e.g. cyber incivility scales) or they lack content validity as they do not tap cyber-specific behaviours (e.g. the cyber NAQ). We therefore aimed to fulfil the need for a workplace cyberbullying measure by developing a scale with sufficient construct and content validity to assess exposure to cyberbullying across working populations. Evidence for the reliability and validity of the 17-item WCM was established during three studies involving 944 participants. Confirmatory factor analyses provided evidence for the validity of a single factor model and also a two-factor model comprising work-related cyberbullying and person-related bullying. Given the substantial correlation between the two factors and the minimal difference in fit for both models, we chose to adopt the single factor model.

The WCM is comprised of 17 behavioural items that assess exposure to negative work-related acts experienced through technology and a self-report definition item that captures the power disparity criterion. Nielsen et al (2010) note that behavioural inventories alone do not assess whether respondents perceive a power imbalance between themselves and the perpetrator, which is a key element of the theoretical definition. In cyberbullying contexts, there are a multitude of factors that may produce a perceived power imbalance, 
including the time and location a target is contacted by the perpetrator, a divergence in technological ability and perpetrator anonymity. Hence, it is important to include the selfreport item when administering the WCM, because it can capture the various ways that respondents may feel powerless compared with the perpetrator. In this respect, we contend that the correlation between the behavioural scale and the self-report item can be used as a validation check: higher correlations confirm that respondents who experience more behaviours more frequently also tend to perceive themselves as being less capable of defending themselves. Furthermore, it should be noted that the power criterion was congenital in the development of the 17 items. The theoretical definition (which includes the notion of power) was used to generate the behavioural descriptions, it was also used by SMEs to evaluate face validity and a significant positive relationship was observed between the behavioural scale and the self-report definition item.

The nomological network of the WCM was established as its pattern of intercorrelations with a wide range of variables conformed to expectations. The WCM was highly correlated with traditional bullying which was unsurprising given similarities in conceptualisation. The WCM also correlated strongly with cyberaggression, which conforms to logic as one would expect cyberbullying victims to encounter cyberaggression. Whilst some of the study results suggest that traditional bullying and cyberbullying represent identical constructs, other analyses suggest that cyberbullying has predictive value over and above traditional bullying.

The WCM explained a small, but significant amount of incremental variance in emotional exhaustion over and above the other harassment variables. One potential explanation for this finding is that cyberbullying spans time and space boundaries, which means that employees may be exposed to cyberbullying outside of their working hours. This may in turn prevent psychological detachment and recovery from work, which is negatively 
associated with emotional exhaustion (Sonnentag et al., 2010). However, researchers have suggested other reasons why cyberbullying may explain additional variance in outcomes. Coyne et al. (2016) suggest that the boundaryless nature of cyberbullying may lead to a more severe impact because cyberbullying acts can quickly be distributed to everyone within an organisation. Furthermore, Ford (2013) found that perpetrator anonymity amplified the association between virtual harassment and fear of future harassment. The value of the WCM lies in its ability to investigate whether these unique features moderate the relationship between cyberbullying and outcomes. Olweus (2012) contends that systematic efforts are needed to determine whether the unique features of cyberbullying actually influence target reactions, or whether these differences have relatively little effect over and above traditional bullying. The WCM can help answer such questions, as well as others concerning prevalence, duration and risk groups.

The current study contributes to the workplace bullying literature by fulfilling the need for a cyberbullying measure that is relevant to the context of work. Researchers can now utilise the WCM rather than adapting traditional bullying measures or using scales developed to assess other cyber harassment constructs. The WCM is broader than existing cyber harassment scales because it assesses behaviours experienced through various technologies that individuals use in relation to their work, rather than through a specific medium. The WCM can therefore obtain a more complete picture of cyberbullying experiences and it is more resilient to technological developments because items do not reference specific media that could become outdated in future years. The measure also provides researchers with a homogenous method of assessing workplace cyberbullying, which allows for comparisons across studies and samples. Finally, Bowling et al (2015) suggest that multiple measures are needed for each form of workplace abuse as this enables a greater understanding of a phenomenon at the construct level. 


\section{Practical Applications}

The WCM provides organisations with a list of indicators that employees find unacceptable which can aid the establishment of policies and avoid confusion regarding normal practise. In a study that detailed an update to their workplace bullying checklist (WBC), Fox and Cowan (2015) state that human resources professionals (HRPs) can use the information at their disposal to create organisational training on what constitutes bullying. West et al. (2014) found that one problem facing HRPs is the difficulty of developing policies for cyberbullying because it is not well defined. As such, the definition and indicators of workplace cyberbullying developed during this study can be used to establish policies and guidelines. The self-labelling item could also be combined with the behavioural scale to create a four-by-four matrix that allows organisations to determine the level of cyberbullying among the workforce. If a notable proportion of staff consistently report high behavioural exposure, organisational-level interventions should be implemented, especially if high selflabelling is reported in conjunction.

When administering the scale, practitioners should consider the response format. In this study the 'at least weekly' and 'daily' categories were collapsed as the latter was rarely selected, indicating that the daily category may be redundant. However, research is needed to determine the average duration of cyberbullying cases. Unlike traditional workplace bullying cases, organisational outsiders can perpetrate cyberbullying more easily, which could produce shorter-lived experiences. Neall and Tuckey (2014) recommend assessing the perpetrator of harassment when using bullying measures. This would allow administrators of the WCM to identify whether it has come from within or outside the organisation. Practitioners should also consider how to ensure the pre-item instructions have been read and understood. One option in this regard would be a tick box that respondents check to confirm the instructions have been understood. 


\section{Study Limitations}

Self-report data were used to construct and validate the measure. This may have caused respondents to either under report or over report their exposure to workplace cyberbullying behaviours. Critics of the self-report methodology state that participants may respond in a socially desirable manner rather than in the way that best reflects their experiences and opinions. Therefore some individuals may have underreported their exposed to cyberbullying as acknowledgement of victimisation could prompt feelings of vulnerability (van Beest \& Williams, 2006). Attempts were made to reduce the risk of common method bias as the anonymous treatment of study results was outlined and participants were clearly advised that they could withdraw from the research at any time (Conway \& Lance, 2010).

Second, because we aimed to create a measure that would be resilient to changes in technology, medium specific items were eliminated. This limits the scale because it does not allow discrimination between communications media, which have different characteristics that could affect a cyberbullying experience. Similarly, it could be argued that the WCM does not capture certain features that underpin certain cyberbullying experiences, such as anonymity and visibility. However, given that these features fall outside the definitional parameters of the construct it may actually be more appropriate to examine them as antecedents or moderators of workplace cyberbullying. For example, anonymity could be a causal factor in cyberbullying perceptions. Indeed, the WCM may be combined with other measures to investigate how specific features of cyberbullying affect employees. For instance, Ford (2013) investigated the unique aspects of virtual harassment by using a general cyberaggression measure combined with separate measures that assessed anonymity, location and media richness. 
A further limitation concerns the estimation methods used to evaluate model fit across the studies. ML estimation was employed during Study 2, whereas WLSMV estimation was used during Study 3. Einarsen et al (2009) used WLS estimation to analyse the factor structure of the NAQ as they suggested that the response categories were ordinal rather than interval. However, other researchers have used a maximum likelihood estimator during the development of bullying scales, which is more compatible with continuous data (Escartin et al., 2010). This disparity reflects an ongoing debate in scale research which concerns whether Likert scale data should be treated as ordinal data or interval data (Norman, 2010). Since the response scale of the WCM is not strictly equal, WLSMV estimation is arguably a more appropriate estimator, especially given the measure's distribution. However during Study 2 ML estimation was employed which influenced retention decisions. Therefore it should be noted that the number of items retained may have been different if WLSMV estimation had been used in Study 2.

\section{Conclusion}

In response for arguments stating that different types of bullying should be investigated and evaluated differently (Hoel et al, 2004; Escartin et al, 2010) this study developed a workplace cyberbullying measure. Systematic research is needed to determine differences between traditional bullying and cyberbullying, and whether the development of the latter construct adds value. We hope that the WCM can prove a useful tool during this endeavour.

Acknowledgements: We would like to thank the anonymous reviewers who provided valuable feedback that improved this article. We would also like to thank Felicity Lawrence for helping to administer the Study One survey within the APS. 


\section{References}

Anderson, L. M., \& Pearson, C. M. (1999). Tit for tat? The spiraling effects of incivility in the workplace. Academy of Management Review, 24(3), 452-471.

Bagozzi, R. P., \& Yi, Y. (1988). On the evaluation of structural equation models. Journal of the Academy of Marketing Science, 16(1), 74-94.

Baillien, E., Rodriguez-Munoz, A., Van den Broeck, A., \& De Witte, H. (2011). Do demands and resources affect target's and perpetrators' reports of workplace bullying? A two-wave cross-lagged study. Work \& Stress, 25(2), 128-146.

Baruch, Y. (2005). Bullying on the net: Adverse behavior on e-mail and its impact. Information \& Management, 42(2), 361-371.

Bies, R., \& Moag, J. (1986). Interactional justice: Communication criteria of fairness. In R. J Lewicki, B. H. Sheppard., M. H. Bazerman (Eds.), Research on negotiations in organizations. 1st ed. Greenwich, CT: JAI Press (pp. 43-55).

Bowling, N. A., \& Beehr, T. A. (2006). Workplace harassment from the victim's perspective: a theoretical model and meta-analysis. Journal of Applied Psychology, 91(5), 998-1012.

Bowling, N. A., Camus, K. A., \& Blackmore, C. E. (2015). Conceptualizing and measuring workplace abuse: Implications for the study of abuse's predictors and consequences. In Mistreatment in organizations (pp. 225-263). Emerald Group Publishing Limited.

Branch, S., Ramsay, S., \& Barker, M. (2013). Workplace bullying, mobbing and general harassment: A review. International Journal of Management Reviews, 15(3), 280-299.

Carlson, J. R., Anson, R. H., \& Thomas, G. (2003). Correctional officer burnout and stress: does gender matter?. The Prison Journal, 83(3), 277-288. 


\section{DEVELOPMENT OF A WORKPLACE CYBERBULLYING MEASURE}

Cohen, J. (1988). Statistical power analysis for the behavioral sciences (2nd ed.). Hillsdale, NJ: Lawrence Erlbaum Associates.

Conway, J. M., \& Lance, C. E. (2010). What reviewers should expect from authors regarding common method bias in organizational research. Journal of Business and Psychology, $25(3), 325-334$.

Coyne, I., Farley, S., Axtell, C., Sprigg, C., Best, L \& Kwok, O. Workplace cyberbullying, employee mental strain and job satisfaction: A dysempowerment perspective. International Journal of Human Resource Management, published online ahead of print $26^{\text {th }}$ Feb 2016, 1-28.

Daft, R. L., \& Lengel, R. H. (1986). Organizational information requirements, media richness and structural design. Management Science, 32(5), 554-571.

Day, A., Paquet, S., Scott, N., \& Hambley, L. (2012). Perceived information and communication technology (ICT) demands on employee outcomes: The moderating effect of organizational ICT support. Journal of Occupational Health Psychology, 17(4), 473-491.

D'cruz, P., \& Noronha, E. (2013). Navigating the extended reach: Target experiences of cyberbullying at work. Information and Organization, 23(4), 324-343.

Doane, A. N., Kelley, M. L., Chiang, E. S., \& Padilla, M. A. (2013). Development of the cyberbullying experiences survey. Emerging Adulthood, 1(3), 207-218.

Dooley, J. J., Pyzalski, J., \& Cross, D. (2009). Cyberbullying versus face-to-face bullying: A theoretical and conceptual review. Zeitschrift für Psychologie/Journal of Psychology, 217(4), 182-188. 


\section{DEVELOPMENT OF A WORKPLACE CYBERBULLYING MEASURE}

Einarsen, S. (2000). Harassment and bullying at work: A review of the Scandinavian approach. Aggression and Violent Behaviour: A Review Journal, 5(4), 371-401

Einarsen, S., Hoel, H., \& Notelaers, G. (2009). Measuring exposure to bullying and harassment at work: Validity, factor structure and psychometric properties of the Negative Acts Questionnaire-Revised. Work \& Stress, 23(1), 24-44.

Einarsen, S., Hoel, H., Zapf, D., \& Cooper, C. (2011). Bullying and Harrassment in the Workplace: Developments in Theory, Research and Practice (No. 2nd ed). Crc Press.

Escartín, J., Rodríguez-Carballeira, Á., Gómez-Benito, J., \& Zapf, D. (2010). Development and validation of the workplace bullying scale EAPA-T. International Journal of Clinical Health \& Psychology, 10, 519-539.

Farley, S., Coyne, I., Sprigg, C., Axtell, C., \& Subramanian, G. (2015). Exploring the impact of workplace cyberbullying on trainee doctors. Medical Education, 49(4), 436-443.

Field, A. (2009). Discovering statistics using SPSS. Sage publications.

Ford, D. P. (2013). Virtual harassment: media characteristics' role in psychological health. Journal of Managerial Psychology, 28(4), 408-428.

Fornell, C., \& Larcker, D. (1981). Structural equation models with unobservable variables and measurement error: Algebra and statistics. Journal of Marketing Research, 18(3) 382388.

Fox, S., \& Cowan, R. L. (2015). Revision of the workplace bullying checklist: the importance of human resource management's role in defining and addressing workplace bullying. Human Resource Management Journal, 25(1), 116-130. 
Garrido, L. E., Abad, F. J., \& Ponsoda, V. (2016). Are Fit Indices Really Fit to Estimate the Number of Factors With Categorical Variables? Some Cautionary Findings via Monte Carlo Simulation. Psychological Methods, 21(1), 93-111.

Giumetti, G. W., McKibben, E. S., Hatfield, A. L., Schroeder, A. N., \& Kowalski, R. M. (2012). Cyber incivility@ work: The new age of interpersonal deviance. Cyberpsychology, Behavior, and Social Networking, 15(3), 148-154.

Hair, J. F., Black, B., Babin, B., Anderson, R. E., \& Tatham, R. L. (2006). Multivariate data analysis (Vol. 6). Upper Saddle River, NJ: Pearson Prentice Hall.

Hardesty, D. M., \& Bearden, W. O. (2004). The use of expert judges in scale development: Implications for improving face validity of measures of unobservable constructs. Journal of Business Research, 57(2), 98-107.

Hershcovis, M. S. (2011). "Incivility, social undermining, bullying... oh my!”: A call to reconcile constructs within workplace aggression research. Journal of Organizational Behavior, 32(3), 499-519.

Hinkin, T. R. (1998). A brief tutorial on the development of measures for use in survey questionnaires. Organizational Research Methods, 1(1), 104-121.

Hoel, H., Faragher, B., \& Cooper, C. L. (2004). Bullying is detrimental to health, but all bullying behaviours are not necessarily equally damaging. British Journal of Guidance and Counselling, 32(3), 367-387.

Hong, J. C., Chien-Hou, L., Hwang, M. Y., Hu, R. P., \& Chen, Y. L. (2014). Positive affect predicting worker psychological response to cyber-bullying in the high-tech industry in Northern Taiwan. Computers in Human Behavior, 30, 307-314.

Hu, L., \& Bentler, P. M. (1999). Cutoff criteria for fit indexes in covariance structure analysis: conventional criteria versus new alternatives. Structural Equation Modeling, 6(1), 1-55. 
Keller, T., \& Dansereau, F. (2001). The effect of adding items to scales: An illustrative case of LMX. Organizational Research Methods, 4(2), 131-143.

Kim, J., Egan, T., \& Tolson, H. (2015). Examining the Dimensions of the Learning Organization Questionnaire A Review and Critique of Research Utilizing the DLOQ. Human Resource Development Review, 1-22.

Kim, J. O., \& Mueller, C. W. (1978). Introduction to factor analysis: What it is and how to do it. Beverly Hills, CA: Sage.

Kline, R. (1998). Principles and practice of structural equation modelling. New York: Guilford.

Kowalski, R. M., Giumetti, G. W., Schroeder, A. N., \& Lattanner, M. R. (2014). Bullying in the Digital Age: A Critical Review and Meta-Analysis of Cyberbullying Research Among Youth. Psychological Bulletin, 140(4), 1073-1137.

Lichtenstein, D. R., Netemeyer, R. G., \& Burton, S. (1990). Distinguishing coupon proneness from value consciousness: an acquisition-transaction utility theory perspective. The Journal of Marketing, 54(3), 54-67.

Lim, V. K., \& Teo, T. S. (2009). Mind your E-manners: Impact of cyber incivility on employees' work attitude and behavior. Information \& Management, 46(8), 419-425.

Loevinger, J. (1957). Objective tests as instruments of psychological theory. Psychological Reports, 3, 635-694.

MacKenzie, S. B., Podsakoff, P. M., \& Podsakoff, N. P. (2011). Construct measurement and validation procedures in MIS and behavioral research: Integrating new and existing techniques. MIS Quarterly, 35(2), 293-334. 
Maslach, C., \& Jackson, S. E. (1981). The measurement of experienced burnout. Journal of Occupational Behavior, 2(2), 99-113.

Maslach, C., Schaufeli, W. B., \& Leiter, M. P. (2001). Job burnout. Annual Review of Psychology, 52(1), 397-422.

Matthiesen, S., \& Einarsen, S. (2007). Perpetrators and targets of bullying at work: role stress and individual differences. Violence and Victims, 22(6), 735-753.

Menesini, E., Nocentini, A., \& Calussi, P. (2011). The measurement of cyberbullying: Dimensional structure and relative item severity and discrimination. Cyberpsychology, Behavior, and Social Networking, 14(5), 267-274.

Neall, A. M., \& Tuckey, M. R. (2014). A methodological review of research on the antecedents and consequences of workplace harassment. Journal of Occupational and Organizational Psychology, 87(2), 225-257.

Nielsen, M. B., Matthiesen, S. B., \& Einarsen, S. (2010). The impact of methodological moderators on prevalence rates of workplace bullying. A meta-analysis. Journal of Occupational and Organizational Psychology, 83(4), 955-979.

Niven, K., Sprigg, C. A., \& Armitage, C. J. (2013). Does emotion regulation protect employees from the negative effects of workplace aggression?. European Journal of Work and Organizational Psychology, 22(1), 88-106.

Norman, G. (2010). Likert scales, levels of measurement and the "laws" of statistics. Advances in Health Sciences Education, 15, 625-632.

Notelaers, G., Baillien, E., De Witte, H., Einarsen, S., \& Vermunt, J. K. (2013). Testing the strain hypothesis of the Demand Control Model to explain severe bullying at work. Economic and Industrial Democracy, 34, 69-87. 


\section{DEVELOPMENT OF A WORKPLACE CYBERBULLYING MEASURE}

Notelaers, G., \& Einarsen, S. (2008, June). The construction and validation of the Short Negative Acts Questionnaire. Paper presented at 6th International Conference on Workplace Bullying, Montreal, Canada.

Nye, C. D., Brummel, B. J., \& Drasgow, F. (2014). Understanding sexual harassment using aggregate construct models. Journal of Applied Psychology, 99(6), 1204-1221.

Nye, C. D., \& Drasgow, F. (2011). Assessing Goodness of Fit: Simple Rules of Thumb Simply Do Not Work. Organizational Research Methods, 14, 548-570.

Olweus, D. (2012). Comments on cyberbullying article: A rejoinder. European Journal of Developmental Psychology, 9(5), 559-568.

Parzefall, M. R., \& Salin, D. M. (2010). Perceptions of and reactions to workplace bullying: a social exchange perspective. Human Relations, 63(6), 761-780.

Podsakoff, P. M., MacKenzie, S. B., \& Podsakoff, N. P. (2012). Sources of method bias in social science research and recommendations on how to control it. Annual Review of Psychology, 63, 539-569.

Privitera, C., \& Campbell, M. A. (2009). Cyberbullying: The new face of workplace bullying? CyberPsychology \& Behavior, 12(4), 395-400.

Satorra, A. (2000). Scaled and adjusted restricted tests in multi-sample analysis of moment structures. In R. D. H, Heijmans., D.S.G, Pollock., \& A, Satorra (Eds.), Innovations in multivariate statistical analysis. A Festschrift for Heinz Neudecker (pp. 233-247). London: Kluwer Academic Publishers.

Schat, A. C., \& Kelloway, E. K. (2005). Workplace aggression. Handbook of Work Stress, $189-218$. 
Smith, P. K. (2012). Cyberbullying and cyber aggression. In S. R. Jimerson, A. B. Nickerson, M. J. Mayer, \& M. J. Furlong (Eds.), Handbook of school violence and school safety: International research and practice (pp. 93-103). New York, NY: Routledge.

Smith, P. K., Mahdavi, J., Carvalho, M., Fisher, S., Russell, S., \& Tippett, N. (2008). Cyberbullying: Its nature and impact in secondary school pupils. Journal of Child Psychology and Psychiatry, 49(4), 376-385.

Snyman, R., \& Loh, J. M. (2015). Cyberbullying at work: The mediating role of optimism between cyberbullying and job outcomes. Computers in Human Behavior, 53, 161-168.

Sonnentag, S., Kuttler, I., \& Fritz, C. (2010). Job stressors, emotional exhaustion, and need for recovery: A multi-source study on the benefits of psychological detachment. Journal of Vocational Behavior, 76(3), 355-365.

Spector, P.E. (2014). Survey design and measure development. In T. D. Little (Eds.), The Oxford Handbook of Quantitative Methods, (pp. 170-188). Oxford University Press.

Steiger, J. H. (1980). Tests for comparing elements of a correlation matrix. Psychological Bulletin, 87, 245-251.

Tokunaga, R. S. (2010). Following you home from school: A critical review and synthesis of research on cyberbullying victimization. Computers in Human Behavior, 26(3), 277-287.

van Beest, I., \& Williams, K. D. (2006). When inclusion costs and ostracism pays, ostracism still hurts. Journal of Personality and Social Psychology, 91(5), 918-928.

Weatherbee, T. G. (2007), Cyberaggression in the Workplace: Construct Development, Operationalization, and Measurement, Sobey's School of Business, Saint Mary's University, Halifax. Willard. 


\section{DEVELOPMENT OF A WORKPLACE CYBERBULLYING MEASURE}

Weatherbee, T. G., \& Kelloway, E. K. (2006). A Case of Cyberdeviancy: CyberAggression in the Workplace. In E. K. Kelloway, J. Barling, \& J. J. Hurrell (Eds.), Handbook of Workplace Violence. (pp. 445-487). Thousand Oaks, CA: Sage Publications, Inc.

West, B., Foster, M., Levin, A., Edmison, J., \& Robibero, D. (2014). Cyberbullying at Work: In Search of Effective Guidance. Laws, 3(3), 598-617.

Worthington, R. L., \& Whittaker, T. A. (2006). Scale development research a content analysis and recommendations for best practices. The Counseling Psychologist, 34(6), 806-838.

Zhang, S., \& Leidner, D. (2014, August). Workplace Cyberbullying: The Antecedents and Consequences. Twentieth Americas Conference on Information Systems, Savannah, Georgia. 
Table 1: Principal Axis Factor Analysis: Pattern Coefficients

\begin{tabular}{|c|c|c|c|}
\hline \multirow{2}{*}{\multicolumn{2}{|c|}{ Item }} & \multicolumn{2}{|c|}{ Factor Loadings } \\
\hline & & $\begin{array}{l}\text { Work-related } \\
\text { cyberbullying }\end{array}$ & $\begin{array}{l}\text { Person-related } \\
\text { cyberbullying }\end{array}$ \\
\hline 1. & Received messages that have a negative tone & .70 & .05 \\
\hline 2. & Been unfairly blamed for work problems & .52 & .27 \\
\hline 3. & $\begin{array}{l}\text { Received aggressively worded messages (e.g. using all capital letters, bold font } \\
\text { or multiple exclamation marks) }\end{array}$ & .54 & .05 \\
\hline 4. & $\begin{array}{l}\text { Had another organisational member copy people into messages that reflect } \\
\text { negatively on you }\end{array}$ & .66 & .06 \\
\hline 5. & $\begin{array}{l}\text { Had another organisational member copy people into messages that embarrass } \\
\text { you }\end{array}$ & .43 & .20 \\
\hline 6. & Had your work unfairly criticised & .51 & .36 \\
\hline 7. & Received rude demands from a colleague & .44 & .27 \\
\hline 8. & Been sent conflicting information & .78 & -.19 \\
\hline & $\begin{array}{l}\text { Been pressurised into responding to technology mediated communications at all } \\
\text { times }\end{array}$ & .64 & -.03 \\
\hline 10. & Been bypassed in group communications that are relevant to your work role & .75 & -.06 \\
\hline 11. & Had colleagues ignore your messages & .66 & -.12 \\
\hline 12. & Been the subject of communications that undermine you & .60 & .26 \\
\hline 13. & Received unreasonable work demands & .54 & .13 \\
\hline 14. & $\begin{array}{l}\text { Been the only individual omitted from group messages that are relevant to your } \\
\text { work role }\end{array}$ & .49 & .17 \\
\hline 15. & $\begin{array}{l}\text { Experienced unfair personal criticism (e.g. on your character, appearance, } \\
\text { opinions) }\end{array}$ & .10 & .65 \\
\hline 16. & $\begin{array}{l}\text { Received negative messages from colleagues that were sent to your personal } \\
\text { (non-work) phone/social media account/ email address }\end{array}$ & -.01 & .57 \\
\hline 17. & Received messages that contain false information about you & .22 & .45 \\
\hline 18. & Had negative rumours or gossip spread about you & .10 & .74 \\
\hline 19. & Had personal information shared without your permission & .20 & .46 \\
\hline 20. & Had jokes about you circulated to others & -.12 & .64 \\
\hline 21. & Been called derogatory names & -.09 & .76 \\
\hline 22. & Received messages that contain abusive language aimed at you & -.12 & .77 \\
\hline 23. & Received threatening messages & .09 & .54 \\
\hline 24. & Received messages unfairly questioning your competence & .34 & .49 \\
\hline 25. & Been the only person excluded from social communications between colleagues & .22 & .45 \\
\hline 26. & Had disparaging remarks written about you in messages to the workgroup & .14 & .60 \\
\hline & Eigenvalue & 10.23 & 2.34 \\
\hline & $\%$ variance explained & 39.36 & 9.00 \\
\hline
\end{tabular}


Table 2: CFA using MLM estimation: Items, factor loadings and correlations between workplace cyberbullying factors

\begin{tabular}{|c|c|c|}
\hline Factor & Item & $\begin{array}{l}\text { Factor } \\
\text { loading }\end{array}$ \\
\hline \multirow{10}{*}{$\begin{array}{l}\text { Work related } \\
\text { cyberbullying }\end{array}$} & Received messages that have a disrespectful tone & 0.633 \\
\hline & Been unfairly blamed for work problems & 0.797 \\
\hline & $\begin{array}{l}\text { Received aggressively worded messages (e.g. using all capital letters, bold font } \\
\text { or multiple exclamation marks) }\end{array}$ & 0.597 \\
\hline & $\begin{array}{l}\text { Had another organisational member copy people into messages that reflect } \\
\text { negatively on you }\end{array}$ & 0.661 \\
\hline & Had your work unfairly criticised & 0.746 \\
\hline & Received rude demands from a colleague & 0.759 \\
\hline & Been sent conflicting information & 0.663 \\
\hline & Been bypassed in group communications that are relevant to your work role & 0.584 \\
\hline & Been the subject of communications that undermine you & 0.778 \\
\hline & Received unreasonable work demands & 0.670 \\
\hline \multirow{7}{*}{$\begin{array}{l}\text { Person related } \\
\text { cyberbullying }\end{array}$} & $\begin{array}{l}\text { Experienced unfair personal criticism (e.g. on your character, appearance, } \\
\text { opinions) }\end{array}$ & 0.595 \\
\hline & Had negative rumours or gossip spread about you & 0.682 \\
\hline & Had personal information shared without your permission & 0.682 \\
\hline & Received messages that contain abusive language aimed at you & 0.566 \\
\hline & Received threatening messages & 0.579 \\
\hline & Received messages unfairly questioning your competence & 0.721 \\
\hline & Been the only person excluded from social communications between colleagues & 0.575 \\
\hline
\end{tabular}




\section{DEVELOPMENT OF A WORKPLACE CYBERBULLYING MEASURE}

Table 3: Correlations among Study Three variables

\begin{tabular}{|c|c|c|c|c|c|c|c|c|c|c|c|c|}
\hline & $\mathrm{M}$ & SD & 1. & 2. & 3. & 4. & 5. & 6. & 7. & 8. & 9. & 10. \\
\hline \multicolumn{13}{|l|}{ Demographics } \\
\hline 1. Age & 42.58 & 11.47 & & & & & & & & & & \\
\hline $\begin{array}{ll}\text { 2. } & \text { Gender } \\
(1=\mathrm{M}, 2=\mathrm{F})\end{array}$ & 1.68 & .47 & $-.12 *$ & & & & & & & & & \\
\hline 3. Tenure & 8.80 & 8.51 & $.62 * *$ & $-.16^{*}$ & & & & & & & & \\
\hline \multicolumn{13}{|l|}{ Harassments Variables } \\
\hline 4. WCM & 1.60 & .49 & -.04 & .09 & -.02 & & & & & & & \\
\hline 5. WCM self-report & 1.27 & .62 & -.05 & $.13 *$ & -.04 & $.49 * *$ & & & & & & \\
\hline $\begin{array}{l}\text { 6. Traditional } \\
\text { bullying }\end{array}$ & 1.35 & .50 & .01 & .05 & .00 & $.74 * *$ & $.40 * *$ & & & & & \\
\hline 7. Cyberaggression & 1.75 & 1.01 & .01 & .06 & -.01 & $.75 * *$ & $.52 * *$ & $.65^{* *}$ & & & & \\
\hline \multicolumn{13}{|l|}{ ICT Demands } \\
\hline 8. Hassles & 2.19 & .67 & .01 & .06 & .02 & $.21 * *$ & .08 & $.18 * *$ & $.13 *$ & & & \\
\hline $\begin{array}{ll}\text { 9. Learning } \\
\text { expectations }\end{array}$ & 3.05 & .90 & $.15^{*}$ & $-.24 * *$ & .12 & $.30 * *$ & .10 & $.28 * *$ & $.32 * *$ & $.23 * *$ & & \\
\hline \multicolumn{13}{|l|}{ Outcomes } \\
\hline $\begin{array}{l}\text { 10. Emotional } \\
\text { exhaustion }\end{array}$ & 3.86 & 1.74 & .08 & .06 & .03 & $.35 * *$ & $.25^{* *}$ & $.36^{* *}$ & $.25^{* *}$ & $.22 * *$ & $.18^{* *}$ & \\
\hline $\begin{array}{l}\text { 11. Interactional } \\
\text { justice }\end{array}$ & 4.23 & 1.05 & .06 & .04 & -.01 & $-.50 * *$ & $-.36 * *$ & $-.55 * *$ & $-.47 * *$ & $-.12 *$ & -.10 & $-.28 * *$ \\
\hline
\end{tabular}


Table 4: Hierarchical regression analyses on the effect of traditional bullying, cyberaggression and cyberbullying on emotional exhaustion and interactional justice

\begin{tabular}{|c|c|c|c|c|}
\hline Criteria and predictors & Adjusted R ${ }^{2}$ & $\mathbf{R}^{2}$ Change & Beta & F (df1, df,2) \\
\hline \multicolumn{5}{|l|}{ Emotional Exhaustion } \\
\hline Model 1: Sample & .001 & .002 & .05 & $.61(1,269)$ \\
\hline Model 2: Traditional bullying & .132 & $.136 * * *$ & $.37 * * *$ & $21.48(2,268)$ \\
\hline Model 3: Cyberaggression & .129 & .000 & .02 & $14.31(3,267)$ \\
\hline Model 4: Cyberbullying & .144 & $.018^{*}$ & $.24 *$ & $12.38(4,266)$ \\
\hline \multicolumn{5}{|l|}{ Interactional Justice } \\
\hline Model 1: Sample & -.004 & .00 & .01 & $.01(1,269)$ \\
\hline Model 2: Traditional Bullying & .300 & $.305^{* * *}$ & $-.56^{* * * *}$ & $58.90(2,268)$ \\
\hline Model 3: Cyberaggression & .318 & $.020 * *$ & $-.18 * *$ & $42.94(3,267)$ \\
\hline Model 4: Cyberbullying & .322 & .006 & -.14 & $33.00(4,266)$ \\
\hline
\end{tabular}

